\title{
Prediction of early pregnancy failure by Uterine Artery Color Doppler
}

\section{Authors \\ Dr Divya Yadav Sharma, Dr Anu Pathak, Dr Neha Agarwal}

\section{Introduction}

First Trimester of Pregnancy is Characterized by many important landmarks with regard to ultimate outcome of pregnancy. Concern about the possibility of spontaneous miscarriage is one of the most common reasons women seek evaluation during their first trimester. Between $11 \%$ and $20 \%$ of all clinically recognized pregnancies are lost before the 20th week of gestation. Ultrasonography is the best diagnostic method in detecting early pregnancy complications. Uterine vascular relaxation and the increase in uterine blood flow in early pregnancy appears to be important determinants of pregnancy outcome.

Alterations in the normal uterine perfusion pattern have been noted in pregnancies complicated by blighted ovum and missed abortion.

The vascular remodeling in the maternal-fetal interface may reduce local arterial resistance and thereby increase uteroplacental blood flow. Impairment of this process is associated with pregnancy complications including spontaneous abortion and placental hematoma, intrauterine growth restriction ${ }^{1}$.With the advent of transvaginal color Doppler spiral sonography, new insights into uteroplacental circulation during the first trimester have been obtained. The use of Doppler sonography to analyse blood flow in even terminal branches of the uteroplacental circulation encouraged investigators to try and predict early and late pregnancy complications related to abnormal placentation. ${ }^{2}$

Transvaginal Color Doppler has enabled precise investigation of fetomaternal circulation in early pregnancy. Uterine artery Doppler velocimetry by itself or in combination with other biochemical markers seems to be an effective firsttrimester screening tool for the ultimate outcome of a healthy pregnancy. Therefore, this study was undertaken to examine the change in blood flow impedance of the uterine artery during early pregnancy by highly sensitive Doppler indices.

\section{Materials and Methods}

This study was conducted in Department of Obstetrics and Gynecology and Department of Radiodiagnosis , S N Medical College ,.Agra. The protocol of the study was approved by the Ethical Committee of the hospital and informed consent was obtained from the patients before their participation in this clinical study.

A total of 100 patients coming to Antenatal OPD with gestational age 8 to 11 weeks who were willing for followup, were included in our study. 
After proper history and examination, a transvaginal USG was performed in all patients and these findings were noted:

a) Gestational sac Diameter

b) Crown Rump Length

c) Presence of Cardiac Activity

d) Presence of a Subchorionic Hematoma. . For the purposes of this study only the first scan that showed detectable fetal cardiac activity was considered for the study. Exclusion criteria included multiple pregnancy, ectopic pregnancy, missed abortion, and nonviable pregnancy before 5 weeks gestation with no detectable cardiac activity.

All the patients were asked to come for follow up after two weeks or in emergency in case of bleeding or pain. All patients were prescribed Folic acid supplements and if needed antiemetics.

Doppler examinations were started at the lowest possible color-gain setting. The gain was gradually increased until a flow pattern was detected in both the uterine arteries, (one at a time.). Whenever flow was found, flow velocity waveforms were recorded. The pulsatility index, resistance index, uterine artery systolic/diastolic value, were measured electronically once and recorded. ${ }^{2}$ To predict subsequent pregnancy loss, Doppler findings were adjusted for maternal age, history of previous abortion, presence of subchorionic hematoma, embryonic bradycardia, and gestational age by means of multivariate logistic regression analysis. The cut-off values are used for the ROC curve. Resistive Index > 0.8 was considered as an abnormal Doppler finding. The aim of this study was to test the efficacy of Uterine artery Color Doppler in the Prediction of Early Pregnancy losses

\section{Results}

A total of 100 patients were included in the study. Out of them 31 came with history of threatened abortion. Age, gestational age and parity were closely comparable between women with threatened abortion compared to normal women. We observed that out of the 31 patients who came with threatened abortions $19(61 \%)$ had normal color Doppler findings, while 12(38\%) had abnormal color Doppler Findings. Of the patients of threatened abortions who came with normal Doppler, 14(82\%), had normal outcome in first trimester while $3(18 \%)$, aborted in first trimester (we had not included the lost patients while calculating percentages). The patients of threatened abortion who had a resistant flow at the outset, 4(36\%) continued normally in first trimester while , 7( 64\%) aborted in first trimester. Of the total patients who had abnormal color Doppler, 10(60\%), aborted while7( $40 \%$ ) had normal outcome in first trimester. Of the patients who had normal Doppler parameters, 62(94\%), had normal outcome in first trimester, while 4 (6\%), aborted.

Table 1 Outcome of pts after 2 weeks who came with history of Bleeding Per Vaginum (Missed excluded.)

\begin{tabular}{|l|c|c|c|}
\hline $\mathrm{N}=31$ & $\begin{array}{c}\text { Normal } \\
\text { outcome }\end{array}$ & $\begin{array}{c}\text { Lost to } \\
\text { followup }\end{array}$ & Abortions \\
\hline $\begin{array}{l}\text { Pts with normal Color } \\
\text { Doppler n=19 }\end{array}$ & $14(82 \%)$ & 2 & $3(18 \%)$ \\
\hline $\begin{array}{l}\text { Pts with abnormal Color } \\
\text { Doppler n=12 }\end{array}$ & $4(36 \%)$ & 1 & $7(64 \%)$ \\
\hline
\end{tabular}

Table 2

\begin{tabular}{|c|c|c|}
\hline \multicolumn{3}{|c|}{$\begin{array}{l}\text { Outcome of Patients after } 2 \text { weeks who ha } \\
\text { Abnormal Color Doppler findings } n=19 \\
\text { failed to follow up) }\end{array}$} \\
\hline $\begin{array}{c}\text { Total Num of } \\
\text { Pts }=17\end{array}$ & $\begin{array}{c}\text { Normal } \\
\text { Outcome }\end{array}$ & Aborted \\
\hline $\begin{array}{l}\text { With threatened } \\
\text { abortion }=11\end{array}$ & 3 & 8 \\
\hline $\begin{array}{c}\text { Without Threatened } \\
\text { Abortion }=6\end{array}$ & 4 & 2 \\
\hline Total & $7(41 \%)$ & \\
\hline
\end{tabular}


Table 3

\begin{tabular}{|c|c|c|}
\hline \multicolumn{3}{|c|}{$\begin{array}{l}\text { Outcome of Patients with Normal Color Doppler } \\
\text { findingsafter } 2 \text { weeks } N=76 \text { ( } 10 \text { failed to followup) }\end{array}$} \\
\hline $\begin{array}{l}\text { Total Num of } \\
\text { Pts }=66\end{array}$ & Normal Outcome & Aborted \\
\hline $\begin{array}{l}\text { With threatened } \\
\text { abortion }=17\end{array}$ & 14 & $3(4 \%)$ \\
\hline $\begin{array}{l}\text { Without } \\
\text { Threatened } \\
\text { Abortion = } 49\end{array}$ & 48 & $1(2 \%)$ \\
\hline Total & $62(94 \%)$ & $4(6 \%)$ \\
\hline
\end{tabular}

Senstivity $=$ Num of pts with abnormal color Doppler who aborted (10) x 100 / Num of pts with Abnormal Doppler who aborted + Num of pts with Normal Doppler who aborted $(10+4)=71 \%$

\section{Table 4}

\begin{tabular}{|l|c|c|}
\hline & Abortions & Normal Outcome \\
\hline $\begin{array}{l}\text { Abnormal } \\
\begin{array}{l}\text { Doppler } \\
(\mathrm{n}=17)\end{array}\end{array}$ & $\begin{array}{c}10 \\
\text { A }\end{array}$ & B \\
\hline $\begin{array}{l}\text { Normal } \\
\begin{array}{l}\text { Doppler } \\
(\mathrm{n}=66)\end{array}\end{array}$ & 4 & 62 \\
\end{tabular}

Senstivity $=(a / a+c) \times 100=(10 / 10+4) \times 100=$ $71 \%$

Specificity $=(d / d+b) \times 100=(62 / 62+7) \times 100=$ 90\%

Positive predictive value $=(\mathrm{a} / \mathrm{a}+\mathrm{b}) \mathrm{x} 100=$ $(10 / 10+7) \times 100=59 \%$

Negetive Predictive value $=(\mathrm{d} / \mathrm{d}+\mathrm{c}) \times 100=$ $(62 / 62+4) \times 100=94 \%$

\section{Discussion}

Early pregnancy loss is a common complication of pregnancy in first trimester pregnancy. Impairment of vascular remodeling in the maternal-fetal interface have been extensively associated with the pregnancy complications. ${ }^{7}$. The possibility of identifying the uteroplacental vascular alterations from the implantation process to the end of the pregnancy could provide a perfect diagnostic tool for the clinical management of the early pregnancies and its complications $^{5-}$ Our purpose was to determine whether an abnormal uterine perfusion pattern was associated with subsequent pregnancy loss after fetal cardiac activity was documented.

In this study, blood flow analyses was performed on the uterine artery because first trimester uterine artery values are accepted as the to be one of the successful factors to predict the outcomes of the placental implantation of which is necessary for the continuous of the pregnancy

Our results show that the resistance to blood flow in the uterine artery underwent changes during early pregnancy. The present study showed cases of spontaneous abortion, with impaired growth of the gestational sac, whose UA-RIs remained high (RI > 0.8) or failed to decrease normally between the 5th and 6th week of pregnancy .This was also observed by Burak Ozkan et al (2015). The high UA-RI between the 5th and 6th week of pregnancy may be a cause of spontaneous abortion and reflect impaired vascular remodeling caused by failure of normal trophoblastic invasion at placentation ${ }^{7,8}$.

In our study vascular resistive indexes were higher in the subsequent miscarriage group that the continuing pregnancies. This finding is in agreement with other studies.

Physiologically in the first trimester nearly all of the vascular alterations have occurred in the uterine artery vascular bed and represent the sum of all changes. This could explain the uterine artery systolic/diastolic ratio to be the most promising predictive value for the subsequent miscarriage.

Here we focus on the high Negetive Predictive value $(94 \%)$ of this test because test results with NPV are useful for practitioners when considering unnecessary, costly treatment. Senstivity of a test also called true positive rate, measures the proportion of positives that are correctly identified as such. Therefore color Doppler of uterine artery is a reliable test when the Doppler comes out to be normal since it rarely comes normal when the outcome is worse. However, an abnormal Doppler is not much useful to screen a non reassuring outcome Specificity (also called the true negative rate) measures the proportions of normal dopplers 
who had normal outcomes. A normal Doppler can therefore correctly reject any abnormality.

The strength of the screen test is in its negative predictive value, according to it, if the Doppler is normal, it gives us a confidence that the outcome is good.

In conclusion, this study confirms the important role of color and spectral Doppler in understanding the vascular alterations in the uterine artery and with correspondence to the pathophysiology of the uteroplacental circulation. The altered change of uterine artery may give a new insight into understanding the early stages of the pathophysiology of spontaneous abortion, such as at the first weeks of pregnancy after implantation. However, further studies are needed with larger sample sizes.

Ümmü Özkaya MD 2007To determine whether spectral Doppler measurements obtained from bilateral uterine, arcuate, radial, and spiral arteries in early gestation correlate with adverse pregnancy outcome.

This prospective study has some limitations. First of all, this study was done in a single centre and needs to be confirmed with larger cohort groups. Second, a longitudinal assessment of the uterine artery could be repeated in order to understand the exact blood flow cut-off values for the continuous of the successful pregnancies

\section{Conclusion}

Transvaginal Doppler examination can detect hemodynamic changes in uteroplacental circulation associated with subsequent adverse pregnancy outcome.

Discordant uterine artery pulsatility indexes in the first trimester were strongly associated with subsequent pregnancy loss. This suggests that uterine ischemia may be implicated in certain cases of early pregnancy loss after documentation of fetal cardiac activity during the first trimester. abnormal uterine artery Doppler in low-risk women achieves a sufficiently high performance to justify aspirin prophylaxis in those who test positive.

\section{References}

1. Sebiha O, Ozkaya U, Ozkan S, Ozeren S, Corakçi A. Doppler examination of uteroplacental circulation in early pregnancy: Can it predict adverse outcome? J Clin Ultrasound 2002; 35: 382-86. (doi:10.1002/jcu).

2. Jauniaux E, Burton GJ. Pathophysiology of histological changes in early pregnancy loss.Placenta 2005; 26:

114-23. (doi:10.1016/j. placenta.2004.05.011). [PubMed]

3. Velauthar L, Plana MN, Kalidindi M, Zamora J, Thilaganathan B, Illanes SE, et al.Uterine artery Doppler in the first trimester as a risk factor for adverse pregnancy outcomes: A meta-analysis involving 55,974 women. Ultrasound ObstetGynecol 2013; 43 (5): $\quad$ 500-7. (doi:10.1002/uog.13275).

4. Papageorghiou AT, Leslie K. Uterine artery Doppler in the prediction of adverse pregnancy

outcome. CurrOpinObstetGynecol 2007; 1 9:

(doi:10.1097/GCO.0b013e32809bd964).

5. Hale SA, Schonberg A, Badger GJ, Bernstein IM. Relationship between prepregnancy and early pregnancy uterine blood flow and resistance index. ReprodSci 2009; 16: 1091-96. (doi:10.1177/1933719109341843).

6. ClinObstet Gynecol. 2010 Dec;53(4):87987. doi: 10.1097/GRF.0b013e3181fbb65d. Uterine artery Doppler in first-trimester pregnancy screening. Bahado-Singh $\mathrm{RO}^{1}$, Jodicke C.

7. Australas J Ultrasound Med. 2015 May;18(2):60-66. doi: 10.1002/j.22050140.2015.tb00043.x. Epub 2015 Dec 31. Özkan $\quad \mathrm{MB}^{1}$, Ozyazici $\quad \mathrm{E}^{2}$, Emiroglu $\mathrm{B}^{2}$, Özkara $\mathrm{E}^{3}$. 
8. J Clin Ultrasound. 2007 Sep;35(7):382-6.

Doppler examination of uteroplacental circulation in early pregnancy: can it predict adverse outcome? Ozkaya $\mathrm{U}^{1}$, Ozkan S, Ozeren S, Corakçi A.

9. Ganapathy R, Ayling LJ, Whitley GS, Cartwright JE, Thilaganathan B. Effect of first-trimester serum from pregnant women with high-resistance uterine artery Doppler resistance on extravillous trophoblast invasion. Hum Reprod 2006; 21: 1295-98. (doi:10.1093/humrep/dei482). [PubMed] 10. Pellizzari P, Pozzan C, Marchiori S, Zen T, Gangemi M. Assessment of uterine artery blood flow in normal first-trimester pregnancies and in those complicated by uterine bleeding. Ultrasound Obstet Gynecol 2002; 19: 366-70. (doi:10.1046/j.14690705.2002.00667.x). [PubMed] 